\title{
Presence of Syphacia muris in Wistar Rats of a Conventional Animal Care Facility and Treatment for the Eradication of this Parasitosis
}

\section{Maria Alfonsina Lizárraga*}

IGEVET - Institute of Veterinary Genetic "Ing. Fernando N. Dulout" (UNLP

- CONICET LA PLATA), School of Veterinary Sciences, National University of La

Plata, Argentina

*Corresponding Author: Maria Alfonsina Lizárraga, IGEVET - Institute of Veterinary Genetic "Ing. Fernando N. Dulout" (UNLP - CONICET LA PLATA), School of Veterinary Sciences, National University of La Plata, Argentina.
Received: June 20, 2020

Published: August 26, 2020

(C) All rights are reserved by Maria Alfonsina

Lizárraga.

\section{Abstract}

Laboratory animals are essential in research. Genetic and health quality control enables reliable and reproducible experimental data. A very common disease in rodent colony facilities, is a parasitosis caused by the etiological agent, species: Syphacia muris, which belongs to the filo: Nematoda, to the family: Oxyuridae, is an intestinal endoparasite. The life cycle of this parasite is direct, (there is no intermediate host) has a cycle of 7 to 9 days. Syphacia muris Las infections can alter a humoral host's response to parasitic antigenic stimuli, and cause a Th2-like immune response with the production of elevated cytokines and induce an autoimmunity mediated by Th2 [1]. Therefore a study was carried out in colonies of rats Wistar strain (adult males and females) of a conventional animal care facility of faculty of medicine of the University of Buenos Aires. A total of 36, 32 y 30 rats were tested. Random samples were taken from animals, by Graham's method. Treatments were: treatment A: Ivermectin administered subcutaneously according to the weight of the animal, every 15 days. Treatment B: Ivermectin administered subcutaneously according to the weight of the animal, each week. In treatment C: Ivermectin was administered orally in drinking water at a concentration of $2 \mathrm{ml}$ ivermectin in $500 \mathrm{ml}$ of filtered water, for four days and allowed to rest for 3 days, this treatment was repeated for three weeks. Together, spray cage spraying containing an ivermectin solution was performed: $1 \mathrm{ml}$ in $250 \mathrm{ml}$ of filtered water. The calculated prevalence rate for each treatment was: treatment A: in the first dose $50 \%$ and in the second dose of 75\%. In treatment B: a 75\% rate was obtained at the first and second doses of $80 \%$. In treatment C: it was $0 \%$ in the first and second doses. These results enabled the finding of adequate and effective treatment for the eradication of oxyides. A parasitosis very common and common in all biotheres, but so untreated. Therefore, this work demonstrated that it is possible to be treated, eradicated and controlled to avoid interference and alter experimental responses. However, ensure more reliable results by controlling some variables, such as the health status of animals. Obtaining a good experimental model, applying the uses of 3Rs [10], in terms of reduction when treating infected animals and avoiding the subsequent use of other animals and in refinement when ensuring the welfare of animals.

Keywords: Syphacia muris; Wistar Rats; Ivermectin and Conventional Animal Care Facility

\section{Introduction}

The conventional Animal Care facility is a physical place where laboratory animals are housed, bred and used that must maintain a defined genetic and microbiological quality and a standardized environment according to the species being hosted. Isolation conditions with trained and qualified personnel are required to prevent

Citation: Maria Alfonsina Lizárraga. "Presence of Syphacia muris in Wistar Rats of a Conventional Animal Care Facility and Treatment for the Eradication of this Parasitosis". Acta Scientific Microbiology 3.9 (2020): 69-72. 
infections with microbial contaminations and strict genetic control [3]. Depending on the presence of microorganisms in animals housed in different types of animal care facility can be classified as: pathogen-free or SPF and conventional. Understood by conventional animal care facility, an installation or accommodation area for animals that do not have provisions for a "clean/dirty" traffic flow, with safety and hygiene barriers of an average level [4].

There is a very common parasitosis in rodent colony installations caused by the etiological agent, species: Syphacia muris, which belongs to the edge: Nematode, to the family: Oxyuridae, is an intestinal endoparasite [9]. The life cycle of this parasite is direct, (there is no intermediate host), a cycle of 7 to 9 days. The gravid female migrates from the blind or the colon to the perianal region of the host where they ovipone, the eggs become infectious within 6 to 24 hours. These cause a itching, when the eggs are scratched they enter through the mouth into the food tract of the rodent, once there the eggs hatch and the larvae continue on their way to the blind, where they move through four stages to sexually mature adults. After fertilization the male dies and is eliminated with faeces [8].

In rodents parasitized with a massive infection cause a severe gastrointestinal, with disturbances such as diarrhea, dehydration. Among other negative effects caused. An alteration in weights is observed, causing a decrease in the weight of rats. In addition, some works have shown that oxiuros in rodents modulate immune function, for example: Syphacia muris infections can alter a humoral host's response to parasitic antigenic stimuli, and cause a Th2-like immune response with elevated cytokine production and induce Th2-mediated autoimmunity [1].

Many institutions never manage to eradicate these parasites due to ineffective measures for the identification and treatments detected. Other factors responsible for the persistence of oxiuros may be the longevity of egg viability. The ineffectiveness of traditional sanitation methods are all possible factors.

The most commonly used antiparasitic treatments in recent years for animals such as cattle, pigs, dogs, cats and laboratory animals are of the endectocide type. Ivermectin, the first endectocidal antiparasitic, belongs to the group of macrocyclic lactones derived from natural products obtained by fermentation of organisms of the genus Streptomyces. Endectocides are effective against many parasites at much lower concentrations than most classic antiparasitics. These have a systemic action (acting through the host's blood) of contact and even by ingestion depending on how they are administered. The name endectocidas derives from the fact that in addition to controlling many ectoparasites, such as: mites, scabies, lice, it is also highly effective against numerous endoparasites, especially gastrointestinal nematode helmintos. Endectocides act on GABA receptors in parasite nervous system cells leading to paralysis and death [5].

\section{Materials and Methods}

The animals in this conventional animal care facility were bred under controlled environmental conditions of temperature (2123oC), humidity (70\%) and light (12:12light: darkness). Commercial granulated food (Cooperation, Buenos Aires, Argentina) and filtered water. The animals were housed in rectangular steel cages with a maximum density of 5 animals per cage. For the bed of the animals was used chips that were sterilized by autoclave. The animals' bed was changed three times a week. The cages were disinfected by a manual washing process, with detergent and then immersed in a solution with $2 \%$ sodium hypochlorite.

Three different treatments were applied to 36,32 and 30 adult rats (male and female) of wistar strain.

\section{Treatments were as follows}

Treatment A, injectable ivermectin subcutaneously, in a dilution of $1: 25(1 \mathrm{ml}$ ivertmectin $+24 \mathrm{ml}$ solvent (propylene glycol). For administration, each animal was weighed at weight multiplied by 0.5 micro liter/gram. This treatment was repeated every 15 days. Treatment B; the same form of administration of the drug as in treatment A, was administered subcutaneously to each animal each week. This was repeated for two weeks. Treatment C: Changed the format of the injectable ivermectin drug to soluble ivermectin for drinking water. $2 \mathrm{ml}$ ivermectin was placed in $500 \mathrm{ml}$ of filtered water. This ivermectin solution is supplied to each cage for four days. He was allowed to rest for 3 days, this treatment was repeated for 3 weeks. In conjunction with the spray of the cages by spray containing $1 \mathrm{ml}$ ivermectin in $250 \mathrm{ml}$ of filtered water.

At the end of each treatment, samples were taken in the perianal region of the rat using Graham's method. The preparations were analyzed under optical microscope, in an increase of 10X. The pres- 
ence and absence of Syphacia muris eggs was recorded. A prevalence rate was obtained for each treatment.

\section{Results}

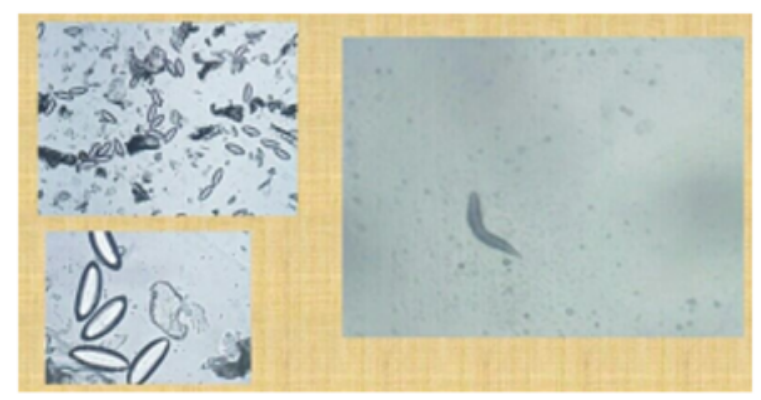

$\mathbf{A}$

B

Figure 1: A) - Identification and recording of Syphacia muris eggs seen at 10X magnification. B) - Adult female of Syphacia muris observed at $10 \mathrm{X}$.

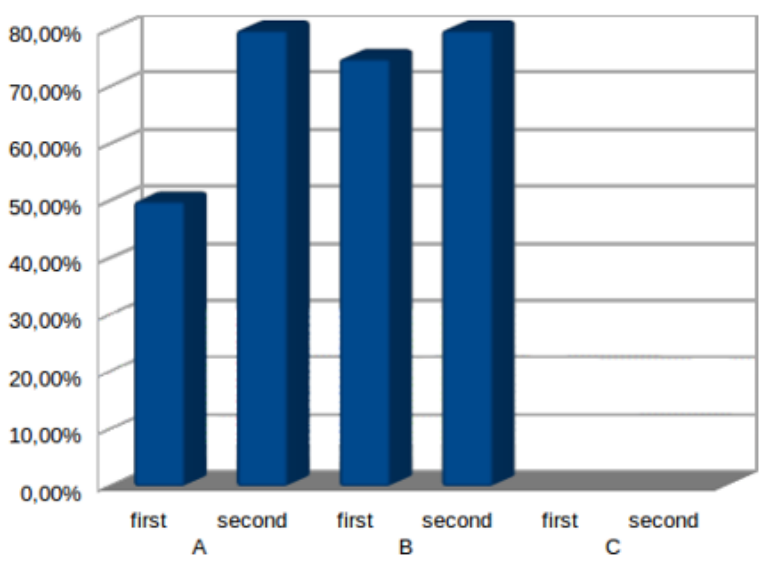

Figure 2: Comparison between the prevalence index obtained from treatment $A$ for the first and second doses: 50 and $80 \%$. Treatment $B$ in the first and second dose: 75 and $80 \%$. Treatment $\mathrm{C}$, in the first and second dose; $0 \%$.

\begin{tabular}{|c|c|c|c|c|}
\hline Treatment & Dose & $\begin{array}{c}\text { Rats } \\
\text { infected }\end{array}$ & $\begin{array}{c}\text { Total } \\
\text { Wistar } \\
\text { rats }\end{array}$ & $\begin{array}{c}\text { Prevalence } \\
\text { index }\end{array}$ \\
\hline A & first & 18 & 36 & $50 \%$ \\
\hline & second & 24 & 30 & $80 \%$ \\
\hline B & firts & 24 & 32 & $75 \%$ \\
\hline & second & 24 & 30 & $80 \%$ \\
\hline C & first & 0 & 30 & $0 \%$ \\
\hline & second & 0 & 30 & $0 \%$ \\
\hline
\end{tabular}

Table 1: Prevalence index of rats infected with Syphacia muris.

\section{Discussion and Conclusion}

The eradication and control of these parasites are extremely difficult. There are different pharmacological treatments, used with more or less successes in the treatments of oxiuros, such as ivermectin, tiabendazole, piperazine administered in drinking water, among others [7]. Therefore there is a continuous search, on a better oxiuros therapy. Since there are very few jobs that report successes. This work represents a contribution of how to eradicate and control oxiuros, Syphacia muris in a conventional animal care facility. In which the presence of Syphacia muris is recorded in Wistar rats. A prevalence rate of infected animals was determined. Comparing prevalence rates, indices de prevalencia, obtained between treatments A and B, was higher (between 70 and 80\%) compared to treatment $\mathrm{A}$, which was $0 \%$. Treatment $\mathrm{A}$ turned out to be the most effective. It is important to establish deworming protocols and rigorous control of animals admitted from other animal care facility. Constant monitoring of animal rooms. It is recommended to take samples every 15 days to assess the health condition of laboratory animals with respect to Syphacia muris.

Conventional animal care facility take few measures to eradicate these parasites. Most learn to live with them. They classify the parasitic burden of their animal care facility as harmless. However, there are works showing that Syphacia muris infection generates in the Wistar rat, an immune response characterized by the predominance of Th2 [1].

Autoimmune diseases have been treated with parasitic helmintos and their products. By modifying the immune response of its carrier in such a way that they inhibit the inflammatory response 
[2]. In studies with Wistar rats to model autoimmune diseases such as autoimmune orchitis, rheumatoid arthritis, where it is necessary to replicate the disease and symptoms in laboratory rats. For further pharmacological, immunological studies. The presence of Syphacia muris, interfere with the response that you want to produce for this type of disease, where a Th1 response that produces inflammation is required. The presence of Syphacia muris inhibits inflammation, as it polarizes a predominant Th1-th2 response. Parasites are also factors of negative confusion, in other models, for example mice, non-obese diabetics, show a reduction in the incidence of dependent insulin diabetes mellitus [6].

Therefore it is essential to carry out a health monitoring. Tofold an antiparasitic such as ivermectin in adult animals and ensure the welfare anima, when treating a very common but untreated parasitosis in conventional animal care facility. Consider the use of the 3Rs [10]. Reduction and refinement through the proper use of animals from laboratories with controlled sanitary and genetic quality. To prevent the misuse of animals and contribute to the welfare of experimental animals. Check the reproducibility, scientific validity of the results of research generated from laboratory animals.

\section{Acknowledgments}

Dr. Giovambatistta for accept me at the Institute of Veterinary Genetics and Dr. Carbone for their scientific advice regarding laboratory animals.

\section{Conflict of Interest}

The authors declare no conflict of interest.

\section{Bibliography}

1. Cortez. A., et al. "Study of the immune response against Syphacia muris in Wistar rat". Biomedica Magazine 31 ( 2011): 209-421.

2. Garfias C. "Parasitic helminths of veterinary concern: host immune response regulation and potential use for the treatment of inflammatory diseases". Revista Veterinaria México 40 (2009).

3. Cardoso de Martínez C., et al. "The animal as an experimental subject. Technical and ethical aspects. Interdisciplinary Center for Studies in Bioethics". University of Chile (2007).
4. Molina M. "Characterization of biotheres used in scientific research" . Bachelor's thesis. University of Costa Rica. (2002): $1-132$.

5. Diaz M. et al. "Pharmacology of endectocides: therapeutic use (II)". Revista Veterinaria 16. (2000): 15-40.Murcia -España.

6. Pohlmeyer-Esch G. "Implications of infectious agents on results of animal experiments". Laboratory Animal 1 (1999): 3987.

7. Lionel Zener. "Effective eradication of pinworms (Syphaciamuris, Syphacia obvelata and Aspiculuris tetraptera) from a rodent breeding colony byoral anthelmintic therapy". Laboratory Animals 32. (1998): 337-334.

8. Oldham, J. "Helminths, ectoparasites, and protozoa in rats and mice". In Pathology of laboratory rats and mice”. (1967): 641679.

9. Martinez C., et al. "Intestinal worms in rodents". The international Journal of Laboratory Animal Science and Welfare 10 (1976): 1-11.

10. Russell W and Burch R. "The principles of human experimental technique". London (1959).

\section{Assets from publication with us}

- Prompt Acknowledgement after receiving the article

- Thorough Double blinded peer review

- Rapid Publication

- Issue of Publication Certificate

- High visibility of your Published work

Website: www.actascientific.com/

Submit Article: www.actascientific.com/submission.php

Email us: editor@actascientific.com

Contact us: +919182824667 